\title{
Emotions Over Time: Synchronicity and Development of Subjective, Physiological, and Facial Affective Reactions to Music
}

\author{
Oliver Grewe, Frederik Nagel, Reinhard Kopiez, and Eckart Altenmüller \\ Hannover University of Music and Drama, Germany
}

\begin{abstract}
Most people are able to identify basic emotions expressed in music and experience affective reactions to music. But does music generally induce emotion? Does it elicit subjective feelings, physiological arousal, and motor reactions reliably in different individuals? In this interdisciplinary study, measurement of skin conductance, facial muscle activity, and self-monitoring were synchronized with musical stimuli. A group of 38 participants listened to classical, rock, and pop music and reported their feelings in a two-dimensional emotion space during listening. The first entrance of a solo voice or choir and the beginning of new sections were found to elicit interindividual changes in subjective feelings and physiological arousal. Quincy Jones' "Bossa Nova" motivated movement and laughing in more than half of the participants. Bodily reactions such as "goose bumps" and "shivers" could be stimulated by the "Tuba Mirum" from Mozart's Requiem in 7 of 38 participants. In addition, the authors repeated the experiment seven times with one participant to examine intraindividual stability of effects. This exploratory combination of approaches throws a new light on the astonishing complexity of affective music listening.
\end{abstract}

Keywords: emotion, chill, music, physiology

But when the ship was within the sound of a man's shout from the land, we fleeing swiftly on our way, the Sirens espied the swift ship speeding toward them, and they raised their clear-toned song: "Hither, come hither, renowned Odysseus, great glory of the Achaeans, here stay thy barque, that thou mayest listen to the voice of us twain. For none hath ever driven by this way in his black ship, till he hath heard from our lips the voice sweet as the honeycomb, and hath had joy thereof and gone on his way the wiser. (Homer's Odyssey, Book XII, Butcher-Lang translation)

The hero Odysseus had to block the ears of his companions with wax and made them tie him to the mast of his ship to escape the fatal song of the sirens. Is this powerful, "magical" force of music a mere myth, or can it in some way manipulate our emotions in real life? Are there components in music that provoke similar affective reactions in all listeners, independent of acculturation, context, and musical preferences? Basically, there are two schools of thought about this topic: Emotivists believe that music can directly elicit emotions in listeners, whereas cognitivists describe music as a stimulus that can express emotions that are only interpreted by the listener (Kivy, 1990). Up to now, many studies have concen-

Oliver Grewe, Frederik Nagel, and Eckart Altenmüller, Institute for Music Physiology and Musicians' Medicine, Hannover University of Music and Drama, Germany; Reinhard Kopiez, Institute for Research in Music Education, Hannover University for Music and Drama, Germany.

EMuJoy-software can be tested at: http://musicweb.hmt-hannover.de/ emujoy/

This work was supported by the DFG (Al 269-6) and the Centre for Systemic Neurosciences, Hannover.

Correspondence concerning this article should be addressed to Eckart Altenmüller, Institute of Music Physiology and Musicians' Medicine, Hannover University of Music and Drama, Hohenzollernstr. 47, 30161, Hannover, Germany. E-mail: altenmueller@hmt-hannover.de trated on the ability of music to express emotions (Balkwill \& Thompson, 1999; Brown, 1981; Cunningham \& Sterling, 1988; Hevner, 1936; Terwogt \& van Grinswen, 1991). Perceived emotions and felt emotions differ (Gabrielsson, 2002), and one's own emotional experience seems to be the most important reason for listening to music (Panksepp, 1995). This study is an interdisciplinary project that attempts to approach the question: Can the same emotional experiences be generally induced by distinct musical patterns?

\section{Terminology and Concept of Affective Responses}

In the last few years, definitional and conceptual shortcomings in the field of emotion research in music have been increasingly criticized (Konečni, 2003; Scherer, 2004). Different disciplines dealing with emotions in response to music research seem not to have "complementary views of the same phenomenon, but divergent views on substantively different phenomena" (Konečni, 2003). To avoid similar misunderstandings, we would like to now summarize the terminological and conceptual foundation of our work. We chose the term affective response as an overall expression, which is used whenever an observed phenomenon is not sufficiently understood in order to label it more precisely. We are interested in general responses to music, but we avoid the term universal because we have not performed any intercultural comparisons. We consider a reaction as being "generally induced" when it is independent of acculturation and musical preferences, namely, a reaction that can be reliably elicited in a heterogeneous group of listeners. "Emotion" is used according to the component process model presented by Scherer (2004). According to this model, an emotion episode consists of coordinated changes in three major reaction components, which constitute an emotion response triad: physiological arousal, motor expression, and sub- 
jective feelings. Emotions, in contrast to moods, are commonly understood as reactions with a relatively short duration (Rolls, 2005). This suggests that changes in these components may be highly synchronized to adapt optimally to the eliciting circumstances. Furthermore, Scherer distinguished between utilitarian and aesthetic emotions, which differ in appraisal concerning goal relevance. The absence of direct personal relevance in aesthetic emotions leads to rather diffusely reactive physiological and behavioral changes in contrast to distinct and proactive changes in the case of utilitarian emotions, including so-called "fundamental emotions" (Ekman \& Davidson, 1994; Scherer, 2004).

\section{Interdisciplinary Approach}

The components of the preceding emotion response triad require special methodological approaches balanced and coordinated with one another. We hope to overcome some of the limitations of each single method by using a conscientious combination. For each component, we chose one approach to examine the overall reaction to a whole musical piece as well as second-by-second measurements. This enabled us to examine (a) responses to a piece as a whole (these responses will be called the overall condition in the following), (b) distinct musical events causing changes in affective reactions (these responses will be called the second-per-second condition), and (c) possible synchronicity in the above-mentioned emotion components (second-per-second condition). The overall conditions as well as the second-per-second conditions are structured according to the emotion response triad of physiological arousal, motor response, and subjective feeling.

\section{Physiological Arousal Component}

Berlyne (1971) hypothesized in his psychobiological arousal theory a distinct relation between the arousal potential of a stimulus and aesthetic responses. In the course of investigating affective responses to music, many bodily reactions, such as shivers, tears, a lump in the throat, heart palpitation, and so forth, have been observed. Those reactions can be reported by participants and be objectively controlled in part by peripheral physiology measurements. Sloboda (1991) and Panksepp (1995) both concentrated on so-called chill reactions. Chills are peak experiences accompanied by bodily reactions, such as goose pimples or shivers.

Sloboda (1991) used questionnaires to ask about bodily reactions, such as chills, tears, laughter, or a lump in the throat, as affective reactions to complete pieces of music. He found distinct musical events that seem to arouse such distinct bodily reactions. Shivers and goose bumps seem to be related to new or unprepared harmonies and sudden dynamic or textural changes.

Panksepp (1995) used questionnaires to study the emotional reactions of 14 undergraduate students to 14 songs, which they themselves brought along, as well as four additional items provided by the author. Participants listened to the music together in a classroom, reporting their emotional reactions and the number of chills they perceived while listening to the music. He found strong reactions to some of the samples. As one of the strongest stimuli, he described "Making Love out of Nothing at All" by the group Air Supply, which elicited 4.4 chills per min/participant. Based on these studies, we used questionnaires to ask the participants for their overall perceived bodily responses (which they had to remember after the musical piece was over).

Many authors have used physiological measurement to reveal information about the connection between affective states and bodily feelings (Harrer \& Harrer, 1977; Khalfa, Peretz, Blondin, \& Robert, 2002; Krumhansl, 1997; Rickard, 2002, 2004; Witvliet \& Vrana, 1995). Krumhansl (1997) recorded a wide spectrum of physiological measurements of cardiac, vascular, electrodermal, and respiratory functions as well as emotion quality ratings (fear, sadness, happiness) on a second-per-second basis and correlated the averages of the measurements. She found the strongest correlations at the skin conductance level (SCL), increasing significantly during all three reported emotion qualities. Although physiological components seem to be an important factor of emotional responses, reviews of a larger compilation of available studies that compare two or more emotions found little evidence for an emotion-specific physiology (Cacioppo, Klein, Berntson, \& Hatfield, 1993; Ekman \& Davidson, 1994; Stemmler, 1998). Because we were interested in the effect of distinct musical events, as well as possible synchronicity in affective reactions, we decided on a second-by-second measurement of skin conductance response (SCR) as an easily obtainable and reliable indicator of physiological arousal. Even if there is no emotion specific physiology, according to the component process model a physiological reaction is a basic component of emotion. The model reflects the phenomenon of a nonspecific, diffuse physiological reaction in the distinction between aesthetic and utilitarian emotions. The way the affective reaction is interpreted (i.e., which specific emotion is perceived) can be understood using the subjective feeling component.

\section{Subjective Feeling Component}

There may be situations in which we listen to music to influence our physiological arousal and motor responses (e.g., sports, dancing), but one of the main reasons to listen to music is its effect on our subjective feelings (Panksepp, 1995). There are three major theoretical approaches to describe participants' conscious experiences while listening to music: discrete emotion theory, dimension models, and eclectic approaches (Scherer, 2004). In this study we chose the two-dimension emotion space (2-DES) model developed by Russell (1980). Schubert (2004) used this model and found relations between ratings of valence and arousal and the acoustical structure of musical pieces. The affective ratings referred to the interpretation of music but not to the personal affective response. Major arguments against studies that rely exclusively on dimensional models are that they ask for feelings instead of emotions; that is, they control for just one component of emotions (Scherer, 2004). To solve this problem in the present study, we used the model exactly for this purpose and added physiological measurements for the remaining emotion components. Second, the possibility of continuous measurement of feelings does not mean that participants constantly use the input device to express their feelings (Konečni, 2003). A computer mouse or slider may be moved just a couple of times or never while listening to a piece of music. To our knowledge, there is still no valid theory of how often affective reactions change over time. Therefore, in this article the second-per-second data is presented as a time series. Even when participants altered their positions in the 2-DES just at distinct 
times, this could also be used as a source of information. We thought it would be interesting to analyze when the participants altered their reported subjective feelings and whether they did so in response to distinct musical events. This revealed the dynamics between perceived affective states. We, therefore, additionally calculated the differentiation of the second-by-second data to gain this information about dynamic processes within the reported self-monitoring.

Third, it is not clear whether people are capable of expressing their feelings properly on just two axes (valence and arousal), because they are constrained to perform a mental principle component analysis (Scherer, 2004) to "target" the feelings they want to express. The underlying evaluative mechanisms cannot be traced using this method. This is one of the most serious problems using dimensional models, which cannot be solved even today to full satisfaction.

On the other hand, dimensional models offer the representation of many different emotions: They are reliable and economical and allow for second-by-second measurement. Being aware of the preceding problems, we nevertheless found the 2-DES to be the most adaptive tool to meet our intention of identifying distinct musical events and synchronicity of affective responses. We modified the approach of Schubert (Schubert \& Dunsmuir, 1999) by asking for felt, instead of perceived, emotions (Gabrielsson, 2002). Participants were explicitly asked to concentrate on their own feelings and not to rate the expression of emotions. For the overall rating, we used additional questionnaires after each piece of music.

\section{Motor Expression Component}

In a music-listening experiment that uses physiological measurements, checking for the motor expression component becomes a difficult task. Participants were asked to sit in an armchair so that their possibilities to move were highly constrained. To take into account the restricted mobility during the experiment, we included the "wish for movement" in the questionnaires. In the event that the music was intended to motivate motor expression, this was made known to the listener, especially when motor expression was suppressed due to the experimental setting.

Another possibility to control for spontaneous motor reactions to music is to measure facial muscle responses (Witvliet \& Vrana, 1995). Witvliet and Vrana (1995) examined facial electromyographic (EMG) data collected at the zygomatic (smiling) and corrugator (frowning) muscles in relation to the dimensions valence and arousal (an explanation of the two-dimensional emotion space will follow). Zygomatic muscle tension was significantly greater during positive than during negative valence affects and greater during high arousal than during low arousal contexts. In contrast, corrugator activity was higher in negative valence and low arousal contexts. Facial reactions are part of a typical emotional reaction pattern and seem to be universal (Ekman \& Davidson, 1994). Therefore, we decided to record the electromyogram of zygomatic and corrugator muscles for the second-bysecond measurements.

\section{Hypothesis and Aim of This Study}

Based on the cited literature, we drew up the hypothesis that distinct musical patterns can generally induce emotions. In previ- ous studies, music was shown to affect three major emotion components: physiological change (Krumhansl, 1997; Sloboda, 1991; Witvliet \& Vrana, 1995), motor activation (Witvliet \& Vrana, 1995), and subjective feelings (Krumhansl, 1997; Schubert, 2004). Our aim was to describe the capacity of entire musical pieces to alter the overall emotional state (feelings, bodily reactions, motor activation) and to identify distinct musical events that induce significant changes in all three emotion components.

\section{Method}

\section{Participants}

Thirty-eight participants (mean age: $38, S D: 16$, range: 11-72 years, 29 females and 9 males) were tested. Participants were contacted personally and were not paid. The group consisted of 5 professional musicians, 20 amateur musicians who play or once played an instrument, and 13 participants that had never played any instrument. We tried to keep the tested group heterogeneous to avoid bias due to age and social or educational context. Most importantly, our participants had various musical tastes (some preferring classical music, others pop, etc.); two of them were not even interested in music at all.

\section{Materials and Task}

Questionnaires. We used a researcher-developed questionnaire based on seven-point scales. Participants were asked to rate their knowledge of, appreciation of, and their perceived pleasantness of each piece. Furthermore, the questionnaire contained a list of possible bodily reactions, such as shivers, tears, lump in the throat, and so forth. This list was based on the results of Sloboda (1991). Questionnaires were asked directly after listening to each piece of music.

Self-monitoring. Participants could continuously report their perceived affective reactions. For continuous measurement of selfreported affective reactions, the EMuJoy software was developed (Nagel, Kopiez, Grewe, \& Altenmüller, in press). We used the two-dimensional emotion space (2-DES) suggested by Russell (Rickard \& Ritossa, 2004; Russell, 1980; Schubert, 2004). The 2-DES was presented to the participants on a computer screen. Participants were asked to rate their subjective feelings continuously on the two axes "arousal" (vertical) and "valence" (horizontal) using a computer mouse as an interface. The difference between recognized and perceived emotions was explained, and participants were explicitly asked not to rate the emotions expressed by the music. Data from EMuJoy was synchronized with physiological and musical data in the range of milliseconds.

Stimuli. As stimuli, seven music pieces from different styles were used. We played entire pieces of music as stimuli instead of excerpts, as we were interested in changes in emotional reactions in the course of a musical piece. Strong emotional reactions may also depend on a broader context of structure and meaning within the piece. These standard pieces were heterogeneous in style, instrumentation, form, among other things. We tried to cover as many styles as possible due to the demand to find general principles in music, not just in one musical style. Four of the stimuli were intended to cover the four extreme points of the 2-DES and were accordingly tested in preexperiments. "Making Love out of 
Nothing at All" was used in a former study by Panksepp (1995). Table 1 shows the list of pieces selected for the experiment:

\section{Technical Devices}

Participants listened to the music via dynamic studio headphones (Beyerdynamic DT 770 PRO) and an USB soundcard (Audiophile, M-Audio). Physiological measurements were recoded with ARBO Ag/AgCl-electrodes (15-mm diameter) and amplified 100 times with a biosignal amplifier developed by the Institute for Explorative Data Analysis (Institut für experimentelle Datenanalyse, IED), Hamburg. The analogous data from the EMuJoy program was digitalized using an A/D converter card (DT 301; Data Translation, Marlboro, MA).

The physiological data, music and data from the EMuJoy were synchronized and recorded using the researcher-developed software based on DT Measure Foundry, Data translation. For time series analysis, physiological data were sampled from $8000 \mathrm{~Hz}$ down to $80 \mathrm{~Hz}$ after low pass-filtering using the signal processing toolbox from Matlab. The down-sampling was executed with the

Table 1

Musical Stimuli and Their Features

\begin{tabular}{|c|c|}
\hline Musical piece & Features \\
\hline $\begin{array}{l}\text { “Tuba Mirum” from Requiem } \\
\text { KV 626, Wolfgang } \\
\text { Amadeus Mozart (Karajan, } \\
\text { 1989) }\end{array}$ & $\begin{array}{l}\text { In this piece of classical vocal music, all } \\
\text { solo voices from bass to soprano as } \\
\text { well as a choir enter one after the } \\
\text { other without any overlap. Thus, the } \\
\text { effect of different voice registers } \\
\text { could be studied. }\end{array}$ \\
\hline $\begin{array}{l}\text { "Toccata BWV 540" Johann } \\
\text { Sebastian Bach (Walcha, } \\
\text { 1997) }\end{array}$ & $\begin{array}{l}\text { This piece for organ was chosen as an } \\
\text { example of (solo-) instrumental } \\
\text { classical music. In this piece of } \\
\text { music, different themes are repeated } \\
\text { and developed in a highly ordered } \\
\text { manner which allows for the study of } \\
\text { the effect of repeated parts compared } \\
\text { to their first appearance. }\end{array}$ \\
\hline $\begin{array}{l}\text { "Making Love out of Nothing } \\
\text { at All" (Air Supply, 1997) }\end{array}$ & $\begin{array}{l}\text { This is an example of pop music which } \\
\text { was formerly used in a study by Jaak } \\
\text { Panksepp (Panksepp, 1995) and was } \\
\text { shown to arouse strong emotional } \\
\text { reactions. }\end{array}$ \\
\hline $\begin{array}{l}\text { "Main Title" Soundtrack of } \\
\text { "Chocolat" Rachel Portman } \\
\text { (2000) }\end{array}$ & $\begin{array}{l}\text { This piece of film music was chosen as } \\
\text { an example for high valence and low } \\
\text { arousal. }\end{array}$ \\
\hline "Coma" (Apocalyptica, 2004) & $\begin{array}{l}\text { Played by the Cello-Rockband } \\
\text { Apocalyptika, "Coma" is a piece that } \\
\text { uses "classical" instruments for rock } \\
\text { music. It was chosen to cause } \\
\text { reactions of low arousal and low } \\
\text { valence. }\end{array}$ \\
\hline $\begin{array}{l}\text { "Skull Full of Maggots" } \\
\text { Cannibal Corpse (Barnes, } \\
\text { 2002) }\end{array}$ & $\begin{array}{l}\text { This piece of death metal music was } \\
\text { rated high on the dimension of } \\
\text { arousal and low on the dimension of } \\
\text { valence. Even if the piece seems to be } \\
\text { nothing but chaotic and noisy, using } \\
\text { the vocal technique "grunting," it has } \\
\text { a clear and simple structure. }\end{array}$ \\
\hline $\begin{array}{l}\text { "Bossa Nova" (Quincy Jones, } \\
\text { 1997) }\end{array}$ & $\begin{array}{l}\text { This piece was rated high in arousal and } \\
\text { in valence. The "Bossa Nova" } \\
\text { represents dance music in the } \\
\text { experiment. }\end{array}$ \\
\hline
\end{tabular}

Table 2

Pictures From International Affective Picture System (IAPS) Used in the Experiment

\begin{tabular}{llc}
\hline \multicolumn{1}{c}{ Rating } & \multicolumn{1}{c}{ Motive } & $\begin{array}{c}\text { Number in IAPS } \\
\text { manual }\end{array}$ \\
\hline High valence/high arousal & Rafting scene & 8,370 \\
& Erotic female & 4,240 \\
Low valence/high arousal & Slit throat & 3,071 \\
& Scene of violence & 3,530 \\
High valence/low arousal & Tiny rabbit & 1,610 \\
& Child & 9,070 \\
Low valence/low arousal & Graveyard & 9,220 \\
& Scene in a hospital & 2,210 \\
Neutral & Spoon & 7,004 \\
& Basket & 7,010 \\
\hline
\end{tabular}

decimate command (Matlab), which uses a Chebyshev Type I filter with a normalized cutoff frequency of $64 \mathrm{~Hz}$ and $0.05 \mathrm{~dB}$ of pass band ripple. For the EMuJoy, data filtering was omitted in order to avoid modifying narrow edges of the self-report data. As human self-report is not expected to change faster than $40 \mathrm{~Hz}$, there was no danger of alias frequencies. For data analysis, the programs Matlab (Version 7.1), Adobe Audition (Version 1.0) and SPSS (Version 13.0) were used.

\section{Procedure}

During the experiment, participants sat in a comfortable armchair, separated from the researcher by a room divider, to create an intimate atmosphere but so as not to leave the participants alone in the room. We also used closed headphones in order to avoid disturbances during the experiment. During the setting of the electrodes, the experiment was explained in a standardized manner. The electrodes for measuring skin conductance were set on the middle sections of the index and middle fingers of the nonactive hand. Electrodes for measuring the electromyograms were placed on m.zygomaticus (smiling) and m.corrugator (frowning) with one reference electrode each. A ground electrode was placed on the back of the active hand. Participants used the active hand to move the mouse on a small table, adjustable to their needs, next to the armchair.

Every session began with a recording of 30 seconds of baseline, during which participants just relaxed and experienced no stimulation.

Afterward a test-tone was played, giving the participants the opportunity to adjust the loudness to an individually comfortable level. Once the participants gave a sign that the experiment could start, 10 pictures from the International Affective Picture System IAPS (Lang, Greenwald, Bradley, \& Hamm, 1993) were presented (see Table 2).

International Affective Picture System. To give participants the opportunity to understand the use of EMuJoy and to have time to practice, a set of 10 pictures from the IAPS had to be rated at the beginning of the experiment. We chose 10 pictures that had received the most extreme values in valence and arousal according to the evaluation in the IAPS manual (numbers apply to the order of the pictures in the IAPS manual). 
The pictures were presented in a nonrandomized order for 30 seconds each without delay between presentations. We decided on a nonrandomized order to avoid starting or ending the picture session with a scene of violence. After the picture session, participants were asked whether they felt comfortable and if they understood the use of EMuJoy. If that was the case, the first piece of music was started.

Musical stimuli. The four pieces, which were assumed to cover the extreme edges of the 2-DES (see Table 1), were presented at the beginning of the experiment in the same order for all participants ("Chocolat", "Coma", "Skull Full of Maggots," "Bossa Nova"). According to preexperiments, we did not expect any series effect. As for the IAPS pictures, we avoided starting or ending the experiment with a presumably negative stimulus ("Skull Full of Maggots"). The remaining three standard pieces ("Tuba Mirum" from Mozart's Requiem, "Toccata BWV 540" by Bach, "Making Love out of Nothing at All") were presented in randomized order. After listening to a piece, participants filled in a questionnaire for that piece. They gave a sign when they were ready to continue, and the next piece was started. The whole procedure took about 2 hours, depending on how much time participants spent to fill in the questionnaires.

\section{Retest Experiment in One Individual}

In an exploratory attempt to test for retest stability, we repeated the experiment with one subject ( 24 , female, right-handed, musician) seven times. The experiment was done on 7 days with a break of 2 days between days 5 and 6 . We used the same pieces in the same order and began the experiment at the same time each day (10:30 a.m.).

\section{Further Data Processing}

Medians of EMuJoy data. In order to reduce high interindividual variability in the responses, we calculated the median. Using means would have caused a strong influence of deviant values. Deviant values could not be excluded because they occurred in different participants at different points in time. To exclude deviant values, it would have been necessary to decide for every second individually which value was deviant. All medians are presented with confidence intervals of the upper and lower quartile.

Differences in EMuJoy data (DEMJ). Differences of data points in intervals of one second were calculated to extract only the necessary information when participants altered their positions in the 2-DES, in other words, when they reevaluated their emotional states. The individual curves were rectified to display movements independent from direction in the 2-DES. The median of the resulting time series indicates how much participants moved on the axes valence and arousal during each second. In that way, we focused on dynamics in affective responses.

Skin conductance data. When recording the Skin Conductance Level (SCL, tonic part), we measured the absolute values of individual skin conductance, which depend on factors, such as the moisture level of the skin, temperature, and blood flow. As a standard procedure, the high pass filtered SCL, the Skin Conductance Response (SCR, phase part) was calculated. In general, SCR reveals changes in SCL during a short period of time; that is, SCR gives information about events, whereas SCL shows just the gen- eral level of sweating, temperature, and blood flow (Boucsein, 2001).

To interpret the data, we calculated the median of the SCR reaction of our participants for both the musical pieces and the IAPS pictures. Normalization did not seem to be an appropriate solution to deal with the data, as most participants showed a high diversity in their responses from one piece of music to the next. Some pieces of music produced a high reactivity both in self-report and in SCR, whereas other pieces showed almost no response in the same person. Since no "absolute" stimulus could be found that triggered the same physiological reaction in all individuals, there was also no reliable maximum for normalization. For this reason SCR was scaled in arbitrary units (AU).

Facial muscle EMG. For facial muscle EMG as a standard procedure of electromyography, the average rectified value (AVR) was calculated. Data were rectified and means were calculated with a moving average of $300 \mathrm{~ms}$.

The first 10 seconds of each piece were not evaluated, because participants showed a strong SC-response, which can be explained as an orientation response to the new stimulus. The strong dynamics in self-report at the beginning of each piece could be due to the fact that all participants moved the computer mouse from the neutral position to their individual rating of their reaction.

Criterion for affective events. Affective events within the time series (DEMJ (Differences in EMuJoy data), SCR, facial EMG were expected to show amplitudes significantly higher compared to the rest of the time series for each piece. Affective events were established in the following ways: (a) To select candidates for affective events, a critical value was established. The percentile of $90 \%$ was calculated for the whole piece for each individual time series. The median of the resulting percentiles was used as the critical value for the median of the DEMJ, SCR and EMG data. All peaks in amplitude of DEMJ, SCR and facial EMG stronger than the critical value were considered as candidates for affective events; and (b) The significance of affective events was tested using a Wilcoxon's test. Values of a chosen peak were tested against the median of the whole piece on an individual level $(p<.05)$.

\section{Rating of Musical Structures}

For the second-per-second condition, we wanted to compare the occurrence of affective events with parallel musical events. In order to identify these musical events, we asked four musical experts (students of the Hanover University of Music and Drama) to analyze our standard pieces. The raters were not informed as to the occurrence of affective events. They were asked to find the beginnings of new parts (segmentation task) and the entrances of a leading voice or choir and to comment on the occurrence of important events within the pieces. Events were used for further analysis if they were identified by at least three of the four expert raters. A delay of 1 to 5 seconds between an event in the musical stimulus and the psychological or physiological reaction was expected (Schubert \& Dunsmuir, 1999).

\section{Results}

\section{Overall Reactions}

Physiological and motor component. After listening to each piece of music, subjects filled in a questionnaire to rate their 

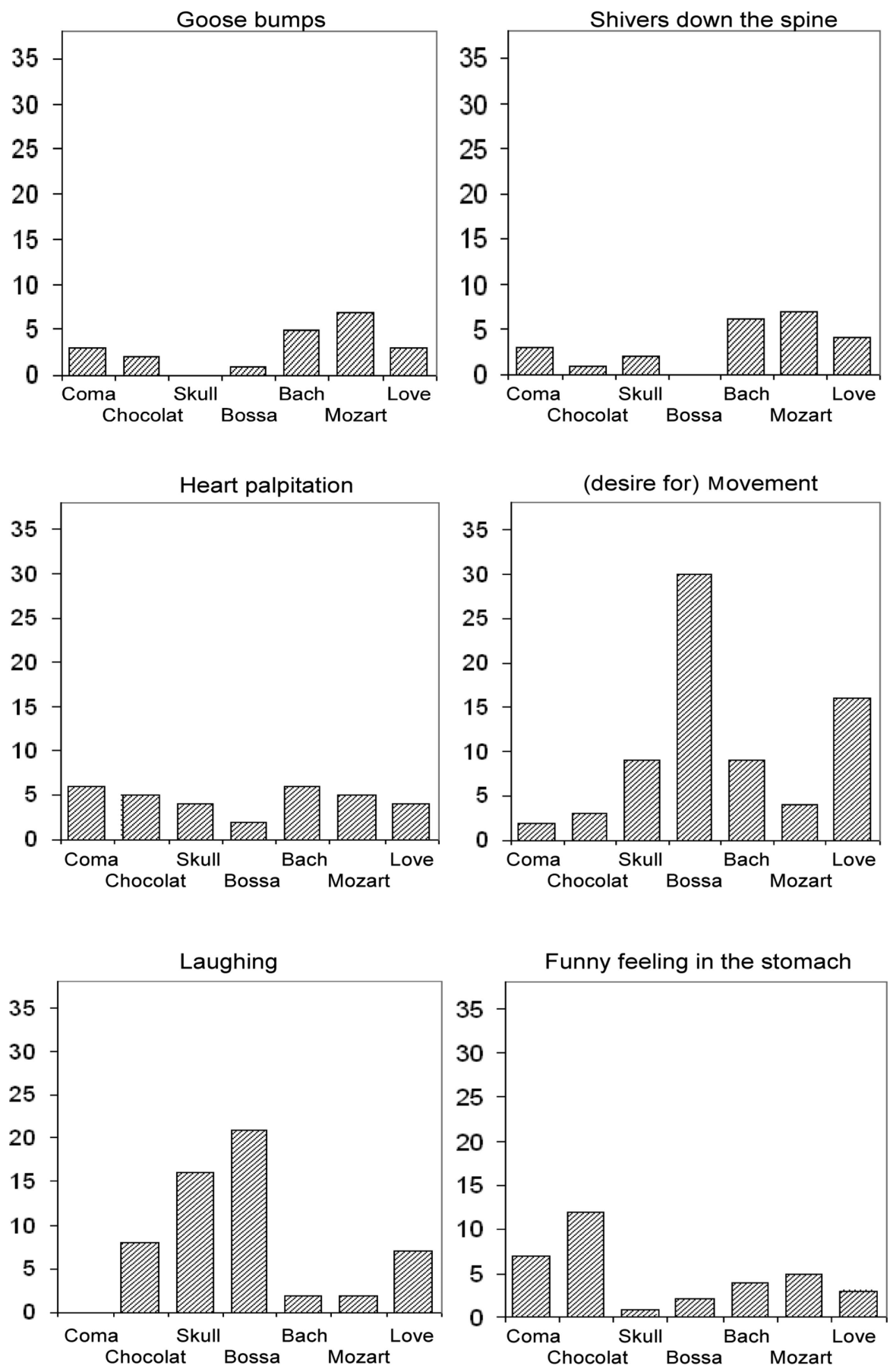

Figure 1. Subjectively reported bodily reactions. Graphs show absolute values of 38 participants who reported the reaction described above in the questionnaire that was filled in after listening to each of the seven musical pieces. Bodily reactions were rated by perceived/not perceived decisions.

overall impression and to report their perceived bodily reactions. Figure 1 shows the bodily reactions that occurred in more than four of the 38 participants in reaction to one of the seven standard pieces: goose bumps, shivers down the spine, movements (or the wish to perform them), laughing, heart palpitation and a "funny feeling in the stomach." Other bodily reactions, such as tears, trembling, blushing, sweating, yawning and a lump in the throat, occurred in less than 4 of the 38 participants.

Reactions that were induced in more than 10 of the subjects were (the desire for) movement, laughing and, for one piece, a funny feeling in the stomach. Most bodily reactions, especially the chill reactions, such as goose bumps and shivers, seemed to be rare 
events that could not be induced in more than seven of the listeners as reactions to the same piece.

Just one piece aroused general reactions in more than 19 (50\%) of the listeners (see Figure 1). The "Bossa Nova" from Quincy Jones induced laughter in 21 and movement in 30 of the subjects.

Subjective feeling component. In the questionnaires, participants also reported how well they knew the piece, how much they liked it, and how much pleasure they felt listening to it on seven-
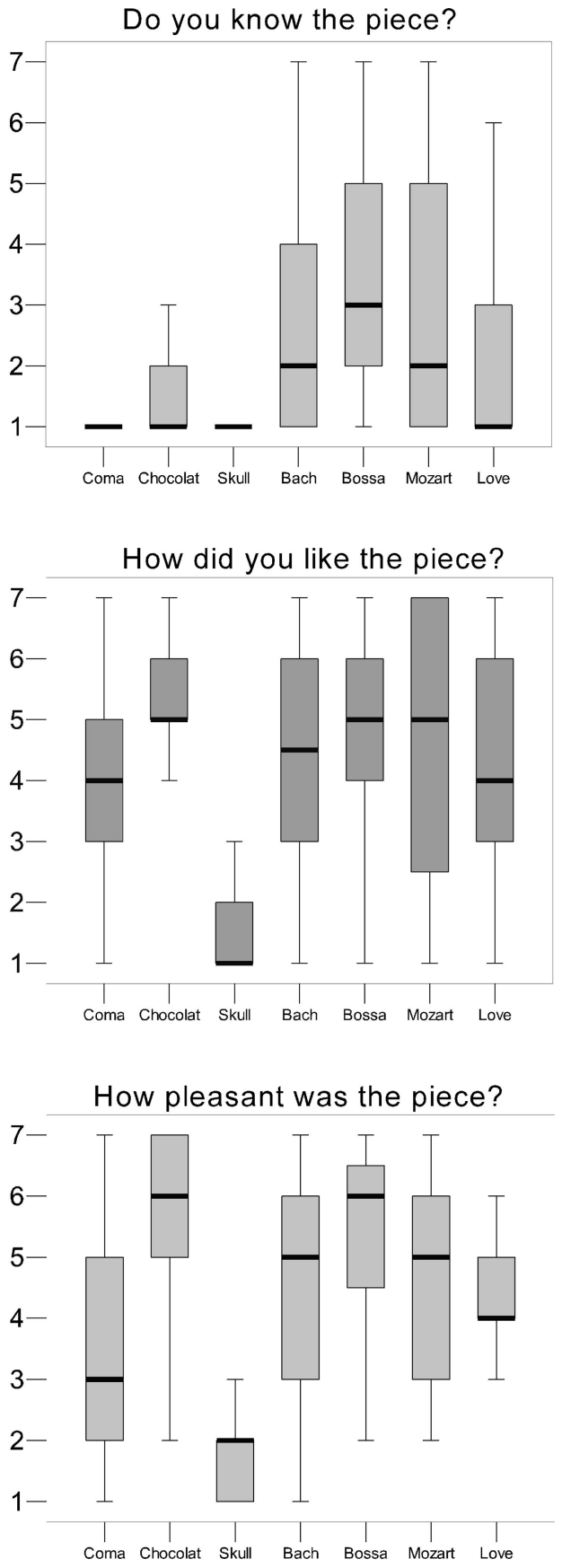

Figure 2. Familiarity, pleasantness, and liking of the seven musical pieces. Boxplots show ratings on 7-point scales in the questionnaire that was filled in after listening to each of the seven musical pieces.
Table 3

Correlation of Familiarity, Liking, and Pleasantness of the Seven Standard Pieces

\begin{tabular}{llll}
\hline & Familiarity & Liking & Pleasantness \\
\hline Familiarity & & \\
Liking & $0.383^{* * *}$ & \\
Pleasantness & $0.385^{* * *}$ & $.889^{* *}$ & \\
\hline${ }^{* *} p<.01$ (Spearman, two-tailed). $N=272$.
\end{tabular}

point scales (see Figure 2). Knowing, liking, and pleasantness correlated to one another (see Table 3).

"Coma," "Chocolat," "Skull Full of Maggots," and "Making Love out of Nothing at All" were unknown to almost all of the participants. The Bach Toccata and Mozart's "Tuba Mirum" showed a high variance in their degree of recognition, but they were unknown to most of the listeners. The best known piece was the "Bossa Nova," which still had a median of 3; in other words, it was not well-known to most participants. Liking and pleasantness show a similar pattern, which is also reflected by the high correlation of these two items. The only piece listeners did not like was "Skull Full of Maggots." "Coma," "Tuba Mirum," and the Bach Toccata were rated ambiguously, with a negative tendency for "Coma" and a positive one for Bach and Mozart. The high ambiguity reflects the different musical tastes of our participants. "Making Love out of Nothing at All" was rated neutral on both scales, whereas "Chocolat" and the "Bossa Nova" were both liked and perceived as pleasant.

\section{Second-per-Second Responses}

Feeling component: self-monitoring in the 2-DES. To give a first overview of the results of the self monitoring, we calcu-

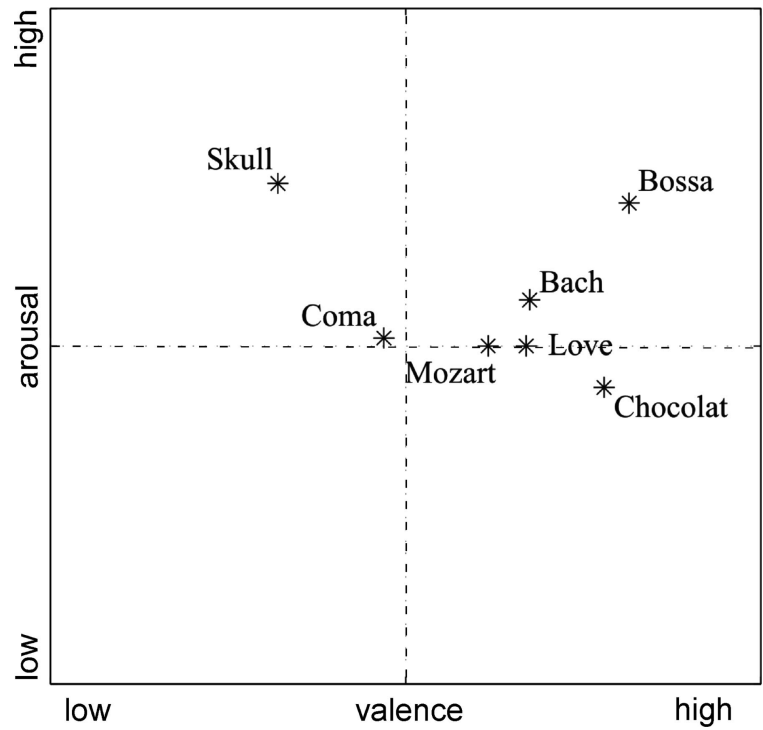

Figure 3. Medians of the second-per-second valence and arousal ratings over time and paticipants for the seven musical pieces. The two scales, ranging from -1 to 1 , are presented as two dimensional emotion space (2-DES) 
lated the median over time for all participants for each piece (see Figure 3).

Of the seven pieces, four were chosen to cover the extreme edges of the 2-DES ("Coma"-low valence/low arousal; "Skull Full of Maggots"-low valence/high arousal; "Bossa Nova"-high valence/ high arousal; and "Chocolat"-high valence/low arousal). None of the four pieces reached extreme values on both axes; however, three pieces were found in the expected quadrants. "Coma" was rated as being almost neutral. None of the seven pieces was rated as having stimulated feelings of both low valence and low arousal. The distribution of the seven pieces on the valence axis reflects almost precisely the overall rating of pleasantness (see Figures 2 and $3)$. In contrast to the finding that SC-response increased with arousal reports in response to pictures (Lang et al., 1993), we

\section{Ratings of Valence and Arousal for Three Example Pieces}
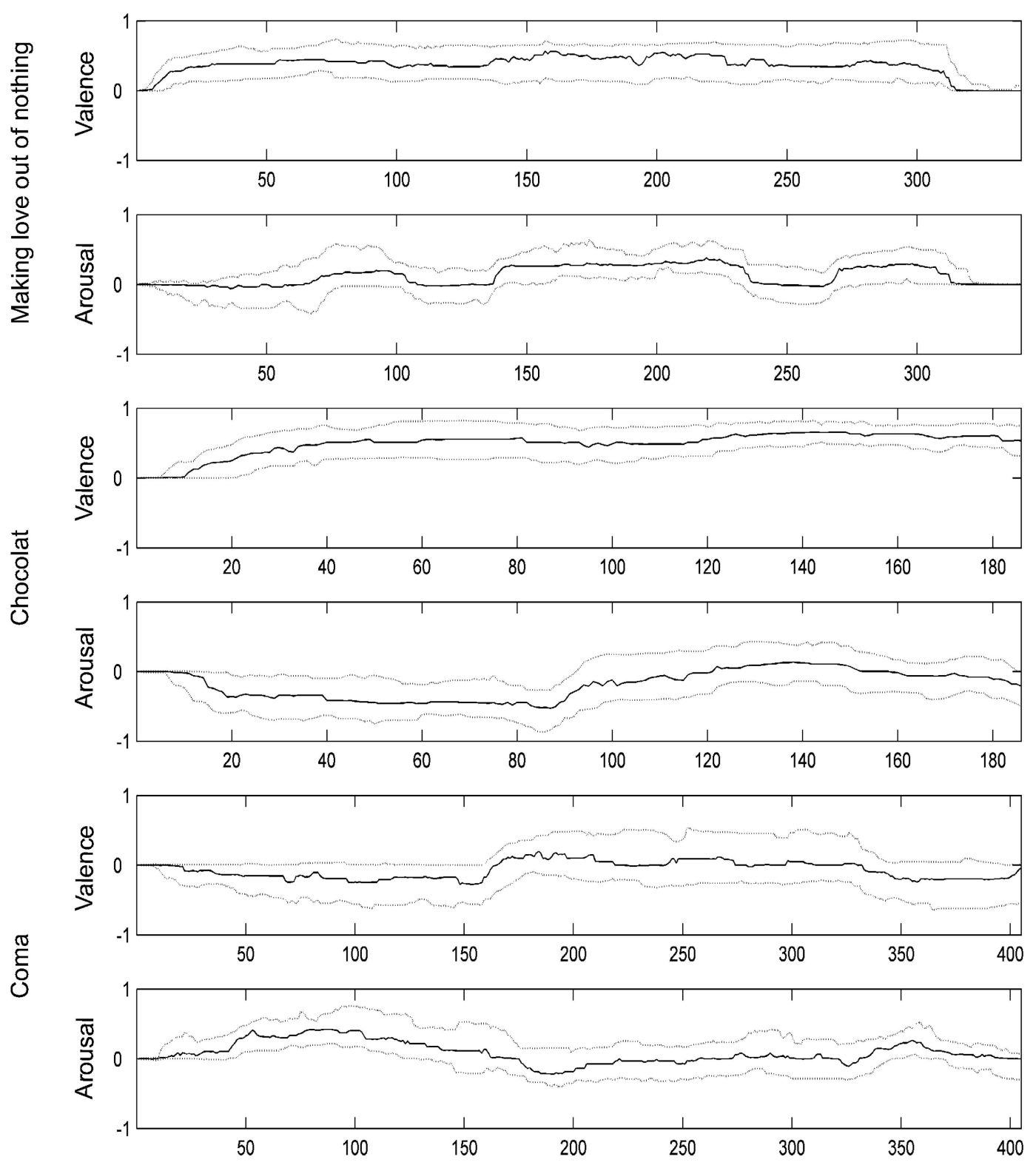

Time $(s)$

Figure 4. Time series analysis of valence and arousal ratings. Median curve of all subjects for three example pieces (second-per-second measurement). Dotted lines represents upper and lower quatile of ratings. Scales range from -1 to 1 , according to the extension of the two dimensional emotion space used in the experiment. 
found a negative relation between these two parameters in response to music. A correlation between the median over time and SCR and the median of arousal resulted in a value of -0.69 , which, however, was not significant $(p>.05)$.

\section{Time Series Data}

Median curves of self monitoring data. In comparing the self monitoring data from the seven pieces, a high diversity in emotional reactions could be observed. The median curves of three of the four pieces selected to cover the four extreme edges of the 2-DES approximately showed the expected direction, but the range of reported feelings was extremely high (see three examples in Figure 4). Of interest, none of the seven pieces covered the lower left quadrant, that is, elicited affective reactions of low valence and low arousal.

Median curves were stable on one level of valence and arousal over time for most pieces, whereas in the individual data, much more development could be seen. Clear changes could be observed in three cases: (1) In the median of arousal in response to "Making Love out of Nothing at All" during sections sung with an elevated voice $(\mathrm{t}=64-90 \mathrm{~s}, \mathrm{t}=136-220 \mathrm{~s}, \mathrm{t}=263-340 \mathrm{~s}$. (2) In the medians of valence and arousal in response to "Coma." Valence is higher and arousal lower during the part in which a melody is performed $(\mathrm{t}=152-320 \mathrm{~s}$, in contrast to a long nonmelodic introduction and coda). 3) In the median of arousal in response to "Chocolat" ( $\mathrm{t}=84 \mathrm{~s})$. The piece consists of two main parts, the second being rated as more arousing.

Interindividual commonality in self-report and SCR. Differentiation-curves contain information only when subjects altered their position in 2-DES. Medians of the differentiationcurves showed significant peaks, revealing events in time. Median curves of the differentiations for two example pieces are shown in Figure 5, together with the median-curves of SCR.

The two examples represent the most different types of music, one being a soundtrack with a soft orchestral sound and the other being an example of death metal, loud and fast guitar and drum "noise" with screaming voices. The extreme difference in appraisal of these two pieces can be seen in "liking" and "pleasantness" of music (see Figure 2). While both pieces show SC-responses of similar strength, "Chocolat" was rated highest (on a seven-point scale) in "liking" (median 5) and "pleasantness" (median 6), whereas "Skull Full of Maggots" was rated lowest (median 1 in liking, median 2 in pleasantness).

As can be seen in Figure 5, subjects showed just a few significant general reactions to each piece. In all seven standard pieces, we found 33 significant general affective events. Three types of affective events occurred: (1) A change in self-report together with an SCR response (open arrow; "Chocolat": $t=25 \mathrm{~s}, \mathrm{t}=125 \mathrm{~s}$ ), namely, a reaction in the subjective feeling component as well as the physiological arousal component. In the seven standard pieces seven affective events of this type occurred. 2) A change in self-report without a significant SC-response (closed arrow; "Chocolat": $t=90$ s, "Skull": $t=45$ s). Of this Type 23 events occurred. 3) A SCR without a significant change in self-report (arrowhead; "Skull": $\mathrm{t}=86 \mathrm{~s}$ ). Three events of this type could be observed. No general motor reactions in facial muscle EMG in response to the seven pieces could be observed. Even in the individual data, a facial response was a rare event.

Musical features, self-monitoring, and physiological reaction. For the psychological and physiological reactions, a delay of 1 to 5 seconds between an event in the stimulus and reaction was expected (Schubert \& Dunsmuir, 1999). As can be seen from the two examples, most of the affective events seem to be related to either the beginning of a new musical section or the entrance of a leading voice or choir. Of interest, this could be found in all pieces, independent of style or other characteristics. Figure 6 shows this as a valid principle for all seven standard pieces.

Up to six out of seven of the affective events that showed both a psychological and physiological reaction could be explained as a response to the most easily recognizable changes within a piece of music. Most of the psychological reactions without significant physiological reactions (21 of 23) and of the physiological changes without significant psychological reactions (two out of three) could be explained by changes in the music. The most frequent type of general response (23) was a psychological reaction without a significant physiological reaction.

\section{Retest in One Individual}

In an attempt to check for retest stability, we repeated the experiment seven times with the same subject, keeping all parameters as constant as possible. Figure 7 shows the results for the two example pieces, "Chocolat" and "Skull Full of Maggots." Median curves of valence and arousal were highly similar to the median curves of the interindividual self-report. The range of responses was smaller for the single subject. No emotion-specific SCR pattern could be found.

Medians of SCR and differentiated curves of self-report show affective events. As in the interindividual experiment, psychological, and physiological responses sometimes occurred together, but seemed to be independent of each other. Some peaks occurred at the same point in time as in the interindividual experiment: for example, the reaction to "Chocolat" at $20 \mathrm{~s}$ and $93 \mathrm{~s}$ in valence and arousal and at $125 \mathrm{~s}$ in SCR. For "Skull Full of Maggots" similar events could be seen after $10 \mathrm{~s}$ and $45 \mathrm{~s}$ in valence and arousal.

Additionally, in the intraindividual condition some significant motor events could be found. The participant showed repeated corrugator activity in response to "Chocolat" at $78 \mathrm{~s}$ and $102 \mathrm{~s} \mathrm{In}$ response to "Skull Full of Maggots," there was repeated corrugator activity at $25 \mathrm{~s}, 48 \mathrm{~s}, 51 \mathrm{~s}$ and $118 \mathrm{~s}$ Just one reaction in corrugator activity occurred parallel to changes in valence and arousal rating (at $48 \mathrm{~s}$, the entrance of the solo vocals in "Skull Full of Maggots"). No parallel reaction in all three emotion components could be found.

\section{Discussion}

Previous studies have found music to be a stimulus that can have an influence on several components of emotional reactions, namely feelings, physiological arousal, and motor reaction (Krumhansl, 1997; Panksepp, 1995; Sloboda, 1991; Witvliet \& Vrana, 1995). Thus, the hypothesis for this exploratory study was that changes in any single emotion component can be observed on an overall as well as a second-by-second level. We combined different psychological and physiological methods in order to find 


\section{Chocolat}
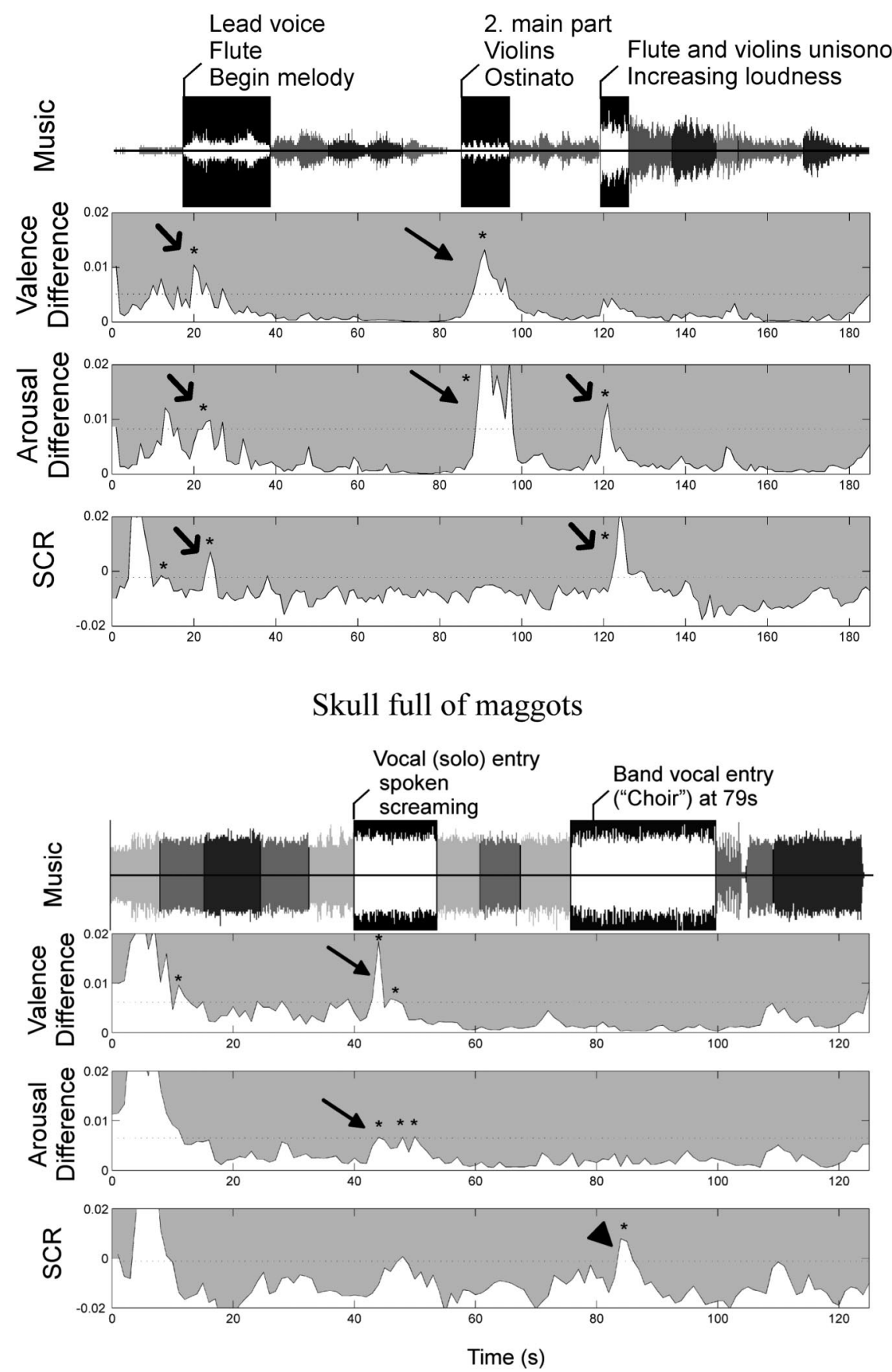

Figure 5. The entry of a voice or choir and beginning of a new part elicit general psychological and physiological processes even in extremely different musical styles. Figure shows two examples out of the 7 musical pieces ("Chocolat" and "Skull Full of Maggots"). Music pieces are presented as envelopes. Musical segments resulting from musicological analysis are represented by different shades of grey. The text above the music envelope lists salient musical events. Differences in valence and arousal (DEMJ) are scaled in distance in emotion space (unfolding from -1 to 1 ). SCR is scaled arbitrary units (see method). Verical [dotted] line indicates "critical value" (upper 10\% of whole curve [percentile]). Open arrows indicate reactions occuring in both DEMJ and SCR reactions. Closed arrows indicate DEMJ reactions without a significant SCR reaction. Arrowheads indicate SCR reactions without a significant self-reported DEMJ reaction. *Wilcoxon $p<0.05$ (second of affective event vs. rest of playtime of this piece). 


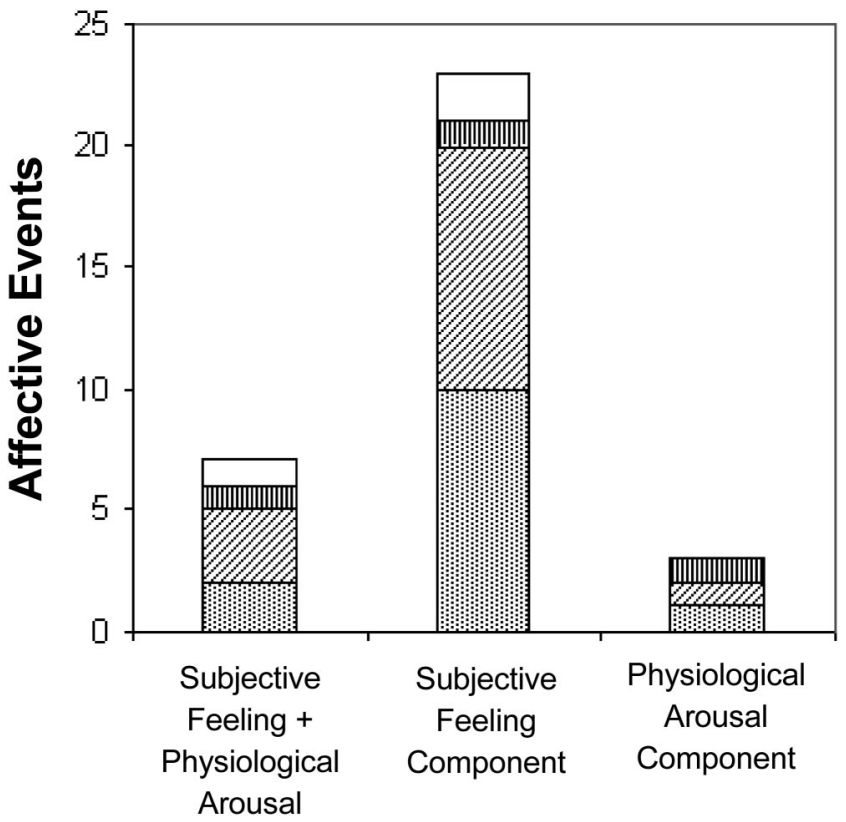

国beginning of a new section $\pi$ entrance of a lead voice
mentrance of a choir $\quad \square$ unexplained

Figure 6. Affective reactions to the entry of a solo voice or choir and to new sections occur in all standard pieces. This figure shows the relation of subjective feeling component (DEMJ) and physiological arousal component (SCR) to easly recognizable musical features. Affective events are in absolute values.

distinct structures in music that influence the different emotion components. We also expected subjective feelings, physiological arousal, and motor components to react in a highly synchronized manner. To investigate whether or not musical patterns can generally induce emotions (rather than just expressing them) independent of the musical tastes of the listeners, we tested stimuli from different musical styles on a heterogeneous group of listeners. In accordance with the previous studies, we were able to establish reactions in all three emotion-component levels.

\section{Overall Ratings}

Physiological arousal component. Regarding the overall physiological arousal, we found reactions, such as chills, goose pimples, and shivers down the spine to be elicited in listeners. In contrast to previous studies (Panksepp, 1995; Sloboda, 1991), according to our results, chills are a relatively infrequent response to music. While Panksepp (1995) found a mean of up to 4.4 chills/min for "Making Love out of Nothing at All" in a group of 14 students, we found chill reactions in response to the same piece in less than seven $(10 \%)$ of our participants. Those listeners who had reported chills had a chill rate of 1.1 chills $/ \mathrm{min}$. There are three possible explanations for this difference: First, Panksepp used a group of participants that was much more homogeneous. Second, the Air Supply song was much better known in 1995 than today, and it seemed to be more familiar to the American students than to the German participants. Finally, the participants in Panksepp's study filled in the questionnaires in a group situation, whereas our participants performed the experiment in individual settings. It cannot be disregarded that chill reactions and emotions in general are influenced by a group situation.

Motor component. Concerning the motor component for the overall level, we found a high level of reactivity to the "Bossa Nova." This finding is true for (the desire to perform) movements as well as for facial reactions (laughing). Participants also reported a high level of overall pleasantness, liking (see Figure 2), and arousal (see Figure 3). According to the literature, we therefore expected a strong reaction in the physiological component too. However, in the physiological component, the "Bossa Nova" had the lowest ratings of all seven pieces with regards to goose pimple reactions, shivers or heart palpitations, and the second lowest for a funny feeling in the stomach. The other pieces showed ambiguous results for different emotion components as well. Similar to the "Bossa Nova," "Making Love out of Nothing at All" showed high ratings for movement, but low ratings in the physiological components. The motor component areas of laughing and movement are the only ones that were elicited in more than 15 of the listeners.

Subjective feeling component. For the subjective feeling component we were able to find the expected reactions for most pieces. The only exception was "Coma," which was chosen to elicit low arousal and low valence but was rated at approximately neutral on both axes. Some relationships to the other emotion components could be confirmed. The extreme ratings for "Skull Full of Maggots" and "Chocolat," for example, seem to be reflected on the pleasantness scale for the funny- feeling-in-the-stomach scale. Besides occasional corresponding results, there seems to be no regularity in the relationships between physiological arousal, motor component, and subjective feelings.

\section{Second-per-Second Measurements}

This finding is confirmed by the results from the second-persecond analysis. Distinct events could be found in response to musical structures in the subjective feeling and the physiological arousal components. In seven cases both domains showed synchronized events in that participants showed a reaction in the feeling component and the physiological arousal component at the same time. Most of the events (23) occur in only one component, though. None of the events could be associated with facial muscle reaction, because no significant events could be found in this component. The affective events from the interindividual experiment in most cases could be confirmed by an intraindividual retest. As in the overall condition, events in the three emotion components show occasional relationships, but no regularity according to our hypothesis could be found.

\section{Does Music Generally Induce Emotions?}

Our experiment used a novel approach: We combined different methodological approaches for each component of the emotion response triad. We tried to understand both the overall and secondby-second reactions to musical pieces. According to our hypothesis that distinct musical patterns can generally induce emotions, we tested a group of 38 listeners with different musical experience and tastes. In accordance with previous literature, we found reac- 

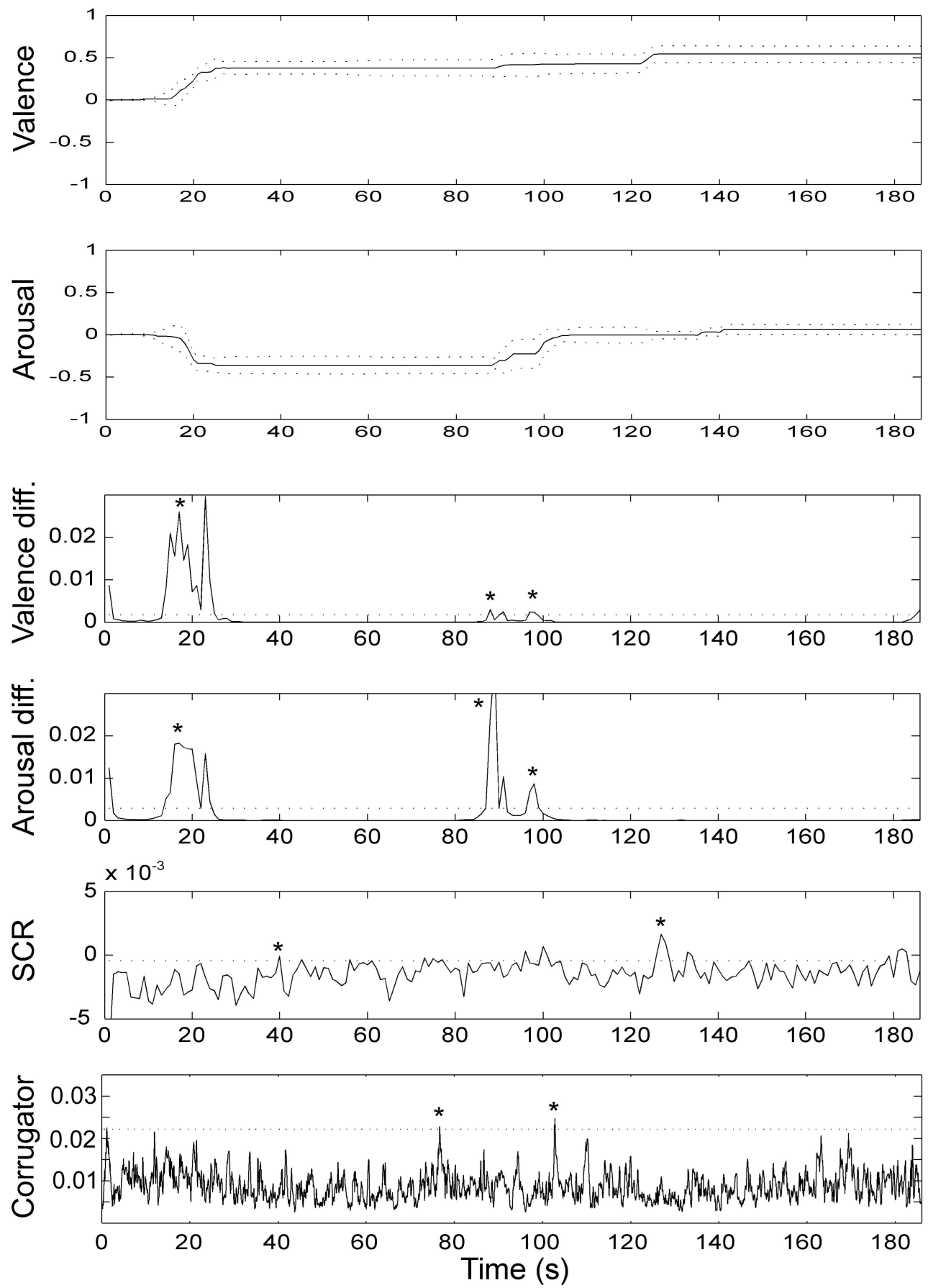

Figure 7. Retest experiment in one individual shows reliability of results. Valence and arousal, differentiated curves of valence/arousal and SCR (all medians) are given for "Chocolat" (a) and for "Skull full of maggots" (b). Medians are of seven sessions in one subject. Valence and arousal (two upper panels) are scaled from -1 to 1 , according to the extension of the two dimensional emotion space used in the experiment. Dotted lines in valence and arousal represent upper and lower quartile of ratings. Differences in valence and arousal (DEMJ) are scaled according to distance in emotion space (unfolding from -1 to 1 ). SCR is scaled arbitrary units (see Method). Vertical [dotted] line in valence/arousal diff. and SCR (three lower panels) indicates "critical value" (upper $10 \%$ of whole curve [percentile]). *Wilcoxon $p<0.05$ (second of affective event vs. rest of playtime of this piece). 
b

Skull full of maggots
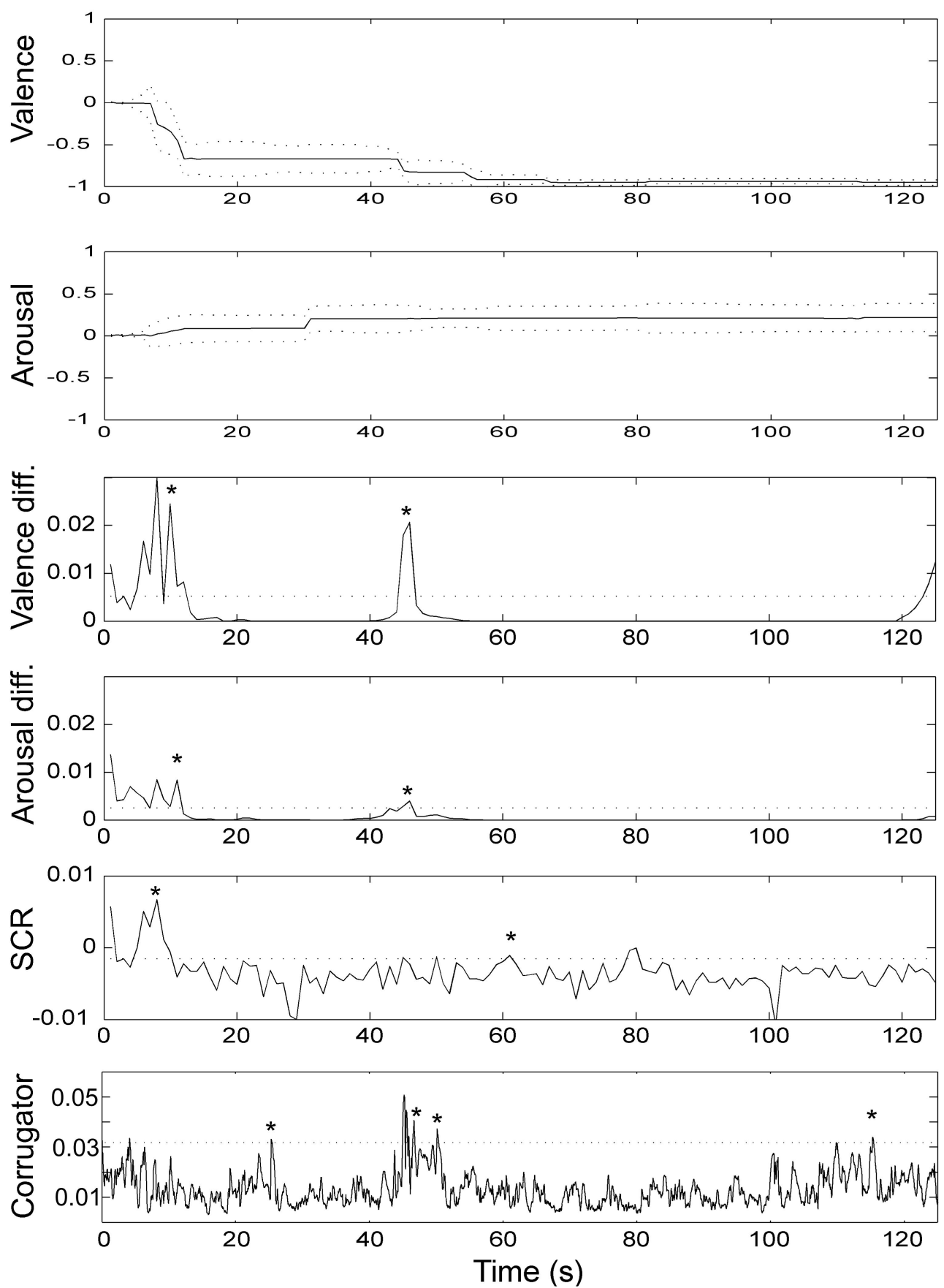

Figure 7. Continued.

tions in each of the three components. However, we could not find any affective events that regularly occurred across all three components in response to any of our stimuli. This is true for the overall condition as well as for the second-by-second measurements. These results suggest that our hypothesis that distinct musical patterns can generally induce emotions should be questioned.
How Could Affective Reactions in the Single Components Be Explained?

Physiological arousal component. In seven extremely different musical pieces, we found seven affective events that led to a parallel subjective feeling and physiological arousal reaction. There is much evidence that these reactions can be interpreted as orienting responses. 
Orienting reflexes are reactions to novelty in stimuli (Rockstroh et al., 1987), and they show a SC-response (Ben-Shakhar, Gati, Ben-Bassat, \& Sniper, 2000; Sokolov, 1990) as one characteristic. Meyer (1956) pointed out that emotions [affects] in response to music depend on violation of expectancies or, in other words, on novelty in music. Six out of seven of the affective events showing both a psychological and physiological reaction could be associated with novelty in the music; for instance, the entrance of a lead voice or choir or the beginning of a new section. Another argument for the interpretation of the general reactions we found as orienting responses is the fact that they show habituation: SC-responses were found for the first entrance of a leading voice, but not when the voice reentered or a section was repeated in the same or a similar way.

Novelty is a necessary but not sufficient condition for orienting responses. Significance is thought to be a second crucial factor (BenShakhar et al., 2000). How and why music can become significant is described in detail in Meyer's article, "Music and Emotion: Distinctions and Uncertainties" (Meyer, 2001). Significance depends in part on familiarity with the musical style. Meyer hypothesized that listeners need a basic implicit or explicit knowledge about the patterns of the music they listen to. When they lack experience with those patterns, they cannot develop implications or expectancies about the progression of the music, which also means that they cannot perceive novelty. Expectancies can only be violated, when there is a preconceived notion of what to expect from a piece. That may be the reason that we did not find a $100 \%$ response, such as a reflex-like stimulusresponse pattern to music. In contrast to many earlier studies (Panksepp, 1995), we had no preselection of a certain social group (e.g., students); rather, we accepted a wide variety of musical education, interests, and social context for our participants. As a consequence, we found only general reactions to the most obvious changes in the musical pieces.

Motor reaction component. In the motor component we found reactions that could be interpreted as being generally induced by the music; 30 of the listeners reported the desire to move, and 21 reported laughter in response to the "Bossa Nova." Because the "Bossa Nova" is a dance, the stimulation of movement is not surprising. In terms of emotion psychology, this affective reaction may be best called motivation. In all cultures and eras music has been and still is important in many social contexts that have to do with coordination and motivation of movements in groups. Examples include military marches, group dancing, fitness courses, or singing while working in the field. Music is thought to be able to establish behavior coherency in masses of people (Huron, 2003).

Subjective feeling component. Most of the affective events we found in the second-per-second condition were subjective feeling reactions without a significant physiological arousal or motor reaction. According to Scherer's component process model, these reactions cannot be considered to be real emotions. Nevertheless, most participants do react in some affective way, which can also be shown by the overall ratings. However, if this reaction is not an emotion, what could it be called? Konečni (2005) discussed this problem in his essay, "The Aesthetic Trinity." He suggested the expression "being moved" in response to music in order to replace terms such as aesthetic emotion or music emotion. Regarding general reactions to music, this seems to be a good possibility to name affective responses properly.

Speaking about "states of being moved" also reflects the ambiguity between overall states and second-per-second events. We found 33 affective events in the listening experiences for the seven pieces, but the overall ratings of valence and arousal were rather stable (see Figure 3). Participants reported an almost steady state in response to music, but at the same time they were moved in that they altered their states. Music is a dynamic aesthetic stimulus in contrast to paintings or architecture, for example, and people seem to react in a dynamic way. Regarding the question of how often affective reactions change over time, we found that listeners report changes in their feelings in response to distinct musical events. All participants used the 2-DES almost continuously, but significant changes occurred only about once or twice a minute, depending on changes in the musical stimulus (see Figure 5). It seems obvious that the subjective feelings during attentive listening to music are not independent of what is expressed by the music. This question will be examined in more detail in a following experiment, asking participants to rate what they think the music is intended to express and to rate their subjective feeling responses.

Retest experiment in one individual. On the individual level, no synchronized events could be found in all three components. Nevertheless, there are examples in which reactions occur on all three levels during the duration of one piece. Thus, on the individual level emotional reactions may possibly be elicited by music. Here we avoid the expression induced, because individual musical experience, tastes, and expectancies are most likely important preconditions for these reactions. Our participant for the retest experiment was a professional soprano herself.

\section{Conclusion}

In this study, we investigated the capacity of music to generally induce emotions. The results presented here give further evidence for the cognitivist position, which views music as a stimulus that cannot induce, but rather can express emotions. The suggestion that musical patterns do not generally induce emotions may be contra-intuitive and must be interpreted in the context of the experimental setting. Due to the technical requirements of physiological measurements, participants listened to music in a laboratory setting, which may influence affective reactions. To avoid the complete exhaustion of our participants, we had to take into consideration the duration of the experiment, and we therefore limited the number of stimuli. The pieces we used were chosen according to the existing literature, but other pieces may have led to different results. Furthermore, we used very strict criteria based on a rather conservative theory of emotion. There are other definitions of emotion which are less strict in their criteria of what defines an emotion. To our knowledge, induction of synchronized emotion components has so far never been shown to occur. However, we decided on the strict criteria in order to avoid misunderstandings and increase understandability. Finally, the suggested conclusion that distinct musical patterns do not generally induce emotions does not rule out its influence on emotion components.

If we interpret the synchronized responses in feelings and physiological arousal component as orienting reflexes, it is at least plausible to think of these general reactions as a starting point for an evaluation process. Scientists agree that orienting responses focus attention on a stimulus, a precondition for cognitive (but not necessarily conscious) evaluation (Ben-Shakhar, 1994; Meyer, 2001; Scherer, 1993). This means that an orienting reflex would not be an emotion, but it could be a starting point for an affective evaluation process and a precondition for an emotion. Initiated by an orienting reflex, a listener 
experienced in a certain style of music may thereby react in an affective and even emotional way to music of the well-known style. But this rather "emphatic" reaction seems to be based on individual experiences and associations. We can be moved and motivated by music, but our "free will" and former experiences remain active components in our reactions.

\section{References}

Air Supply. (1997). Making love out of nothing at all. On Very best of Air supply [CD]: Musicrama.

Apocalyptica. (2004). Coma. On Cult [CD]: USA (Megaphon Importservice).

Balkwill, L. L., \& Thompson, W. F. (1999). A cross-cultural investigation of the perception of emotion in music: Psychophysical and cultural cues. Music Perception, 17, 43-64.

Barnes, C. (2002). Skull full of maggots [Recorded by Cannibal Corpse]. On Eaten back to life [CD]. Simi Valley, CA: Metal Blade Records.

Ben-Shakhar, G. (1994). The roles of stimulus novelty and significance in determining the electrodermal orienting response: Interactive versus additive approaches. Psychophysiology, 31, 402-411.

Ben-Shakhar, G., Gati, I., Ben-Bassat, N., \& Sniper, G. (2000). Orienting response reinstatement and dishabituation: Effects of substituting, adding, and deleting components of nonsignificant stimuli. Psychophysiology, 37, 102-110.

Berlyne, D. E. (1971). Aesthetics and psychobiology. New York: Meredith Corporation.

Boucsein, W. (2001). Physiologische Grundlagen und Meßmethoden der dermalen Aktivität. In F. Rösler (Ed.), Bereich Psychophysiologie (Vol. 1, pp. 551-623). Göttingen: Hogrefe.

Brown, R. (1981). Music and language. Paper presented at the Ann Arbor Symposium: National symposium on the applications of psychology to the teaching and learning of music. (Reston, VA: Music Educators National Conference), 223-264.

Cacioppo, J. T., Klein, D. J., Berntson, G. G., \& Hatfield, E. (1993). The psychophysiology of emotion. New York: Guilford Press.

Cunningham, J., \& Sterling, R. (1988). Developmental change in the understanding of affective meaning in music. Motivation and Emotion, 12, 399-413.

Ekman, P., \& Davidson, R. J. (1994). The nature of emotion (fundamental questions). New York: Oxford University Press.

Gabrielsson, A. (2002). Emotion perceived and emotion felt: Same or different? Musicae Scientiae (Special issue 2001-2002), 123-147.

Harrer, G., \& Harrer, H. (1977). Music, emotion and autonomic function. In M. D. Critchley \& R. A. Henson (Eds.), Music and the brain. Studies in the neurology of music. (2nd ed., pp. 202-216). London: William Heinemann Medical Books Limited.

Hevner, K. (1936). Experimental studies of the elements of the expression in music. American Journal of Psychology, 48, 246-268.

Homer. (1909) The Odyssey (S. H. Butcher and A. Lang, Trans.) With introd. and notes. New York: Collier, The Harvard Classics v. 22.

Huron, D. (2003). Is music an evolutionary adaption? In I. Z. Peretz \& J. Robert (Eds.), The cognitive neuroscience of music (pp. 57-75). New York: Oxford University Press.

Jones, Q. (1997). Soul Bossa Nova. On Music from the original motion picture "Austin Powers" [CD]: Hollywood Records.

Karajan, H. v. (1989). "Tuba mirum” from Requiem KV626. On MozartRequiem [CD]: Deutsche Grammophon (Universal).

Khalfa, S., Peretz, I., Blondin, J-P., \& Robert, M. (2002). Event-related skin conductance responses to musical emotions in humans. Neuroscience Letters, 328, 145-149.

Kivy, P. (1990). Music alone: Philosophical reflections on the purely musical experience. Ithaca, NY: Cornell University Press.

Konečni, V. J. (2003). Review of P. N. Juslin and J. A. Sloboda (Eds.),
"Music and emotion: Theory and research." Music Perception, 20, $332-341$.

Konečni, V. J. (2005). The aesthetic trinity: Awe, being moved, thrills. Bulletin of Psychology and the Arts, 5, 27-44.

Krumhansl, C. L. (1997). An exploratory study of musical emotions and psychophysiology. Canadian Journal of Experimental Psychology, 51, 336-352.

Lang, P. J., Greenwald, M. K., Bradley, M. M., \& Hamm, A. O. (1993). Looking at pictures: Affective, facial, visceral, and behavioral reactions. Psychophysiology, 30, 261-273.

Meyer, L. B. (1956). Emotions and meaning in music. Chicago, London: The University of Chicago Press.

Meyer, L. B. (2001). Music and emotion: Distinctions and uncertainties. In P. N. Juslin \& J. A. Sloboda (Eds.), Music and emotion. Theory and research (1st ed., pp. 341-360). Oxford: Oxford University Press.

Nagel, F., Kopiez, R., Grewe, O., \& Altenmüller, E. (in press). Continuous measurement of perceived emotions in music: Basic aspects of data recording and interface features. Behavior Research Methods.

Panksepp, J. (1995). The emotional sources of "chills" induced by music. Music Perception, 13, 171-207.

Portman, R. (2000). Main titles. On Music from the Miramax motion picture "Chocolat" [CD]. London: Sony Music Entertainment.

Rickard, N. S. (July 2002). Skin conductance differentiates emotionally powerful music from other arousing and emotional stimuli. Paper presented at the 7th international conference on music perception and cognition, Sydney.

Rickard, N. S. (2004). Intense emotional responses to music: A test of the physiological arousal hypothesis. Psychology of Music, 32, 371-388.

Rickard, N. S., \& Ritossa, D. A. (2004). The relative utility of "pleasantness" and "liking": Dimensions in predicting the emotions expressed by music. Psychology of Music, 32, 5-22.

Rockstroh, B., Johnen, M., Elbert, T., Lutzenberger, W., Birbaumer, N., Rudolph, K., et al. (1987). The pattern and habituation of the orienting response in man and rats. International Journal of Neuroscience, 37, 169-182.

Rolls, E. T. (2005). Emotions explained. Oxford: Oxford University Press.

Russell, J. A. (1980). A circumflex model of affect. Journal of Personality and Social Psychology, 39, 1161-1178.

Scherer, K. R. (1993). Neuroscience projections to current debates in emotion psychology. Cognition and Emotion, 7, 1-41.

Scherer, K. R. (2004). Which emotions can be induced by music? What are the underlying mechanisms? And how can we measure them? Journal of New Music Research, 33, 239-251.

Schubert, E. (2004). Modelling perceived emotion with continuous musical features. Music Perception, 21, 561-585.

Schubert, E., \& Dunsmuir, W. (1999). Regression modelling continuous data in music psychology. In S. W. Yi (Ed.), Music, mind and science (pp. 298-335). Seoul: Seoul National University Press.

Sloboda, J. A. (1991). Music structure and emotional response: Some empirical findings. Psychology of Music, 19, 110-120.

Sokolov, E. N. (1990). The orienting response, and future directions of its development. Pavlovian Journal of Biological Science, 25, 142-150.

Stemmler, G. (1998). Emotionen. [Emotions.]. In F. Rösler (Ed.), Enzyklopädie der Psychologie. Ergebnisse und Anwendungen der Psychophysiologie. (Vol. C, I, 5, pp. 95-163). Göttingen: Hofgrefe Verlag für Psychologie.

Terwogt, M. M., \& van Grinswen, F. (1991). Musical expression of moodstates. Psychology of Music, 37, 99-109.

Walcha, H. (1997). Toccata BWV540. On Bach, berühmte Orgelwerke [CD]: Deutsche Grammophon.

Witvliet, C. v., \& Vrana, S. R. (1995). Psychophysiological responses as indices of affective dimensions. Psychophysiology, 32, 436-443.

Received April 7, 2006

Revision received May 1, 2007

Accepted May 1, 2007 